\title{
The importance of listening in communication
}

Fatih Yavuz*,

Ozgur Celik',

Suggested Citation:

Research: New Trends and Issues 7

Abstract 


\section{Introduction}

\section{Statement of the research problem}

\section{Literature Review}

M

4. Purpose of the study 
5. Research question

6. Methodology

\section{Research Participants}

8. Instruments and Procedure

9. Data Analysis 


\section{Recommendations for Further Study}

\section{References}

M The Importance of Teaching Listening in the EFL Classroom

$\mathrm{M}$ Second language acquisition

The language teaching matrix Cambridge M

. Journal of International Social Research, 7

Procedia-Social and Behavioral Sciences, 9 